\title{
A
}

Acta HealthMedica

Volume: 2, Issue: 1, January-March 2017, Pages: 143, DOI: http://dx.doi.org/10.19082/ah143

\section{DESIGN AND IMPLEMENTATION OF A WEB-BASED SYMPTOM CHECKER}

\author{
Parisa Eslami ${ }^{1}$, Reza Safdari ${ }^{1}$, Mahboobeh Bonyadi ${ }^{2}$
}

1: Department of Health Information Management, Tehran University of Medical Science,Tehran,Iran

2: School of Pharmecy, Tehran University of Medical Science,Tehran,Iran

Correspondence:

Dr Reza Safdari, Tel: 02188983025, E-mail: rsafdari@tums.ac.ir

\section{TYPE OF ARTICLE: CONFERENCE ABSTRACT}

\begin{abstract}
Introduction: In today's world, we witness daily increases of using the Internet for self-diagnosis and prognostication by people around the world. For this purpose, most people start with Internet engines such as Google, which can be sometimes confusing and mislead people suffering from urgent symptoms. Therefore, online symptom checkers that effectively provide a potential diagnosis for patients, based on their symptoms, and direct them to the appropriate care setting can be a great replacement. The objective of this study is to develop an application to provide patients with reliable knowledge and encourage them to participate in their health care.

Methods: We have designed and implemented an online decision-support tool to help users select the part of the body that bothers them, choose their symptoms from a structured list, and learn about potential conditions or issues based on their age and gender. The structured list includes nearly 200 clinical conditions subdivided into categories, including head and neck, eyes, ear, nose, throat, chest and back, arms and hands, abdomen and pelvis, legs and feet.

Conclusion: Patients can use the developed system to help them deal with their daily health concerns. It also can be incorporated as part of a personal health record or used by medical students as an educational tool. The online decision support tool will be used in a local or national website to be announced to the users. The accuracy, effectiveness, and user interface should be tested after the announcement of the application.
\end{abstract}

KEYWORDS: E-health service, Diagnostic tools, Health consumers

\footnotetext{
Abstracts of First National Congress of Medical Informatics, Mashhad, Iran, February 2017

(C) 2017 The Authors. This is an open access article under the terms of the Creative Commons Attribution-NonCommercialNoDerivs License, which permits use and distribution in any medium, provided the original work is properly cited, the use is non-commercial and no modifications or adaptations are made.
} 